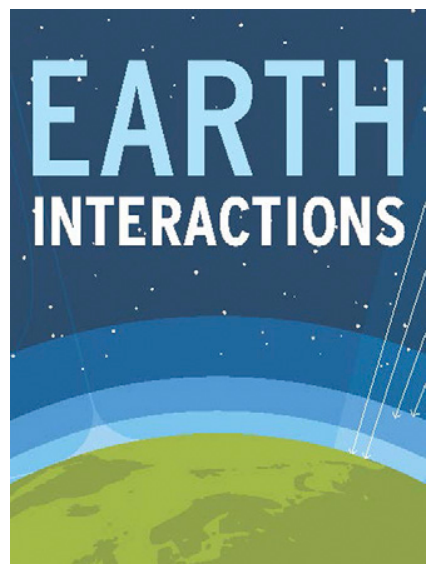

(C) 2018 American Meteorological Society. For information regarding reuse of this content and general copyright information, consult the AMS Copyright Policy (www.ametsoc.org/PUBSReuseLicenses).

\title{
Predicted Land Carbon Dynamics Are Strongly Dependent on the Numerical Coupling of Nitrogen Mobilizing and Immobilizing Processes: A Demonstration with the E3SM Land Model ${ }^{\curvearrowright}$
}

\section{Jinyun Tang a and William J. Riley}

Earth and Environmental Sciences Area, Lawrence Berkeley National Laboratory, Berkeley, California

Received 26 September 2017; in final form 9 April 2018

ABSTRACT: While coupling carbon and nitrogen processes is critical for Earth system models to accurately predict future climate and land biogeochemistry feedbacks, it has not yet been analyzed how numerical methods that land biogeochemical models apply to couple soil mineral nitrogen mobilizing and immobilizing processes affect predicted ecosystem carbon and nitrogen cycling. These effects were investigated here by using the E3SM land model and an evaluation of three plausible and widely used numerical couplings: 1) the mineral nitrogen-based limitation scheme, 2) the net uptake-based limitation scheme,

O) Supplemental information related to this paper is available at the Journals Online website: https://doi.org/10.1175/EI-D-17-0023.s1.

${ }^{\mathrm{a} C}$ Corresponding author: Jinyun Tang, jinyuntang@1bl.gov

DOI: 10.1175/EI-D-17-0023.1 
Earth Interactions - Volume 22 (2018) • Paper No. 11 • Page 2

and 3) the proportional nitrogen flux-based limitation scheme. It was found that these three schemes resulted in large differences (with a range of $316 \mathrm{PgC}$ ) in predicted cumulative land-atmosphere carbon exchanges under the RCP4.5 atmospheric $\mathrm{CO}_{2}$ simulations. This large uncertainty is without accounting for the different representations of the many land biogeochemical processes, but is about $73 \%$ of the range $(434 \mathrm{PgC})$ reported for CMIP5 RCP4.5 simulations. These results help explain the large uncertainty found in various model intercomparison experiments and suggest that more robust numerical implementations are needed to improve carbon-nutrient cycle coupling in terrestrial ecosystem models.

KEYWORDS: Land surface; Numerical analysis/modeling; Ecological models; Land surface model; Biosphere-atmosphere interaction

\section{Introduction}

For past and future carbon-climate feedbacks, Earth system models (ESMs) predict a wide range of terrestrial ecosystem responses to environmental change, including significant changes in terrestrial carbon stocks in response to scenario-based climate change (e.g., Friedlingstein et al. 2014; Hoffman et al. 2014). These uncertain responses were reported in several model intercomparison projects, such as phase 5 of the Coupled Model Intercomparison Project (CMIP5; Hoffman et al. 2014; Shao et al. 2013; Taylor et al. 2012), the North American Carbon Program Multiscale Synthesis and Terrestrial Model Intercomparison Project (MsTMIP; Huntzinger et al. 2012, 2017), and the Trends and Drivers of the Regional-Scale Sources and Sinks of Carbon Dioxide project (TRENDY; http://dgvm.ceh.ac.uk/node/9). These large modeling differences were attributed to several factors, including uncertain input data, uncertain model structures, and uncertain model parameterizations (e.g., Blanke et al. 2016; Clein et al. 2007; Tang and Zhuang 2008; Luo et al. 2015, 2017; Wieder et al. 2015a,b). Further, ESMs have been criticized for ignoring nutrient controls on the terrestrial carbon cycle (e.g., Wieder et al. 2015b). For example, in CMIP5, only the Community Land Model version 4 (CLM4; Oleson et al. 2010) represented the coupling between carbon and nitrogen dynamics (Friedlingstein et al. 2014), even though observations clearly show that nitrogen strongly influences ecosystem carbon responses to climate and anthropogenic perturbations (LeBauer and Treseder 2008; Vitousek and Howarth 1991). Recently, most CMIP6 ESM land models have integrated a variety of approaches to couple carbon and nutrients (mostly nitrogen, but some with phosphorous) dynamics, plant-microbial competition for nutrients, and nutrient regulation of photosynthesis, carbon allocation, and more.

For many models, even when nitrogen cycling is considered, their representations of coupled nitrogen and carbon cycles have been criticized for several deficiencies, including 1) poor mechanistic representation of plant versus microbe nitrogen competition (Zhu et al. 2016a,b, 2017) and 2) the lack of representation of other essential processes that affect nitrogen dynamics (e.g., microbial population processes; Grant 2013). Most existing land biogeochemical models, from site level to ESM scale, perform poorly when confronted with observations from ecosystem perturbations that affect the nitrogen cycle (Bouskill et al. 2014; De Kauwe et al. 2017; Houlton et al. 2015; Zaehle et al. 2014).

Generally, including a new nutrient cycle in a land biogeochemistry model involves two steps: 1) formulating the kinetics of the coupled carbon-nutrient dynamics and 2) numerically implementing the designated kinetic formulation. Specifically, step 1 
Earth Interactions - Volume 22 (2018) • Paper No. 11 • Page 3

relates to how to devise the governing equations of the observed interactions between various abiotic and biotic entities. The uncertainty in step 1 is one of the major causes of model deficiencies discussed in the previous paragraph (and may still exist in CMIP6 models). Since there is currently no unanimously accepted theory of land biogeochemistry, any given process may have multiple representations used by different modeling groups. One example process relates to how plants and microbes compete for nutrients in soil. Our recent survey (Zhu et al. 2017) suggests that there are at least four different ways land biogeochemical models represent this process. In this study, however, we focus on uncertainty associated with issues in step 2, which relates to the fact that the same governing equations are often solved differently by different modelers. Yet, these different numerical methods do not guarantee comparably accurate solutions, which, if not rigorously evaluated, may be numerically inconsistent with the underlying governing equations. This consistency or convergence issue has been discussed intensively in a few other geoscience subdisciplines, including geophysical fluid dynamics, atmospheric chemistry, and marine biogeochemistry (e.g., Arakawa 1966; Broekhuizen et al. 2008; Gross et al. 2018, submitted to Mon. Wea. Rev.; Nguyen et al. 2009; Phillips 1956; Sandu 2001; Tang et al. 2015; Wan et al. 2013, 2017). However, this issue is rarely mentioned in land biogeochemistry model development and only occasionally mentioned in the related field of computational ecology (Petrovskii and Petrovskaya 2012).

Here, using the land module of Energy Exascale Earth System Model (E3SM), we show that three commonly applied numerical couplings of the same mathematical formulation of nitrogen mobilizing and immobilizing processes can lead to significant model prediction differences, which may help explain the wide range in ESM predictions of the terrestrial carbon cycle.

\section{Methods}

\subsection{Different numerical coupling of nitrogen mobilizing and immobilizing processes}

With its improved software modularity (so that different numerical solvers can be applied to a designated formulation of biogeochemistry with a small amount of effort) and better support for consistent updating of the many state variables, the E3SM land model (ELM) together with the biogeochemical reactive transport module BeTR (Tang et al. 2013; see also online supplemental material) is used for this study. ELM-BeTR explicitly considers nitrogen coupling between soil $\mathrm{NH}_{4}^{+}$and $\mathrm{NO}_{3}^{-}$mobilizing and immobilizing processes (Figure 1). The mobilizing processes (marked with the green arrow in Figure 1) are associated with the decomposition of three soil organic matter pools (which release $\mathrm{NH}_{4}^{+}$), and immobilizing processes (marked with blue and red arrows in Figure 1) include plant nitrogen uptake to support plant growth and microbial nitrogen uptake to support decomposition of three plant litter and one coarse woody debris pool, nitrification (which consumes $\mathrm{NH}_{4}^{+}$and produces $\mathrm{NO}_{3}^{-}$and $\mathrm{N}_{2} \mathrm{O}$ ), and denitrification (which consumes $\mathrm{NO}_{3}^{-}$and produces $\mathrm{N}_{2} \mathrm{O}$ and $\mathrm{N}_{2}$ ). The immobilizing processes compete for soil mineral nitrogen to fulfill their metabolic demand. This competition is resolved using the popular relative demand approach, where all mineral nitrogen immobilizing processes are assumed equally competitive, such that their uptake is proportional to their 
CENTURY-like plant-microbial N competition unit

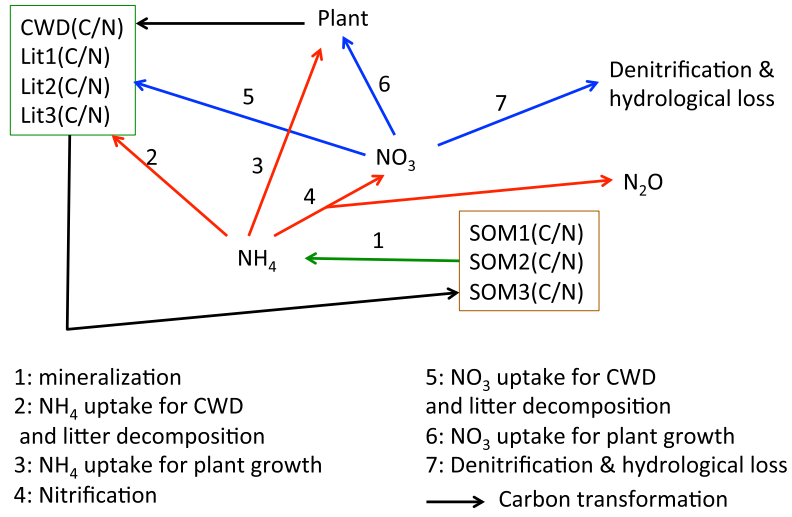

Figure 1. A schematic illustration of how plant and microbial processes compete for different soil mineral nitrogen species. Pathway 1 (green arrow) is the only nitrogen mobilizing process. The red and blue lines indicate immobilizing processes. In competing for soil mineral nitrogen, a demand flux is first computed for each immobilizing process. The total demand is then compared with available nitrogen to either satisfy all immobilizing demands or scale them down using the different coupling schemes described in the main text. A description of how the biogeochemistry of ELM is computed can be found in Oleson et al. (2013).

respective demands in assimilating the two mineral nitrogen species (Goll et al. 2012, 2017a,b; Hidy and Barcza 2014; Parida 2011; Thornton et al. 2007).

With all other biogeochemical processes represented identically, three commonly applied schemes were used to couple nitrogen mobilizing and immobilizing processes within each coupling time step (see Figure 2 for a graphic example). In the first scheme [Mineral Nitrogen-Based Limitation (MNL); second row of Figure 2], only the existing soil mineral nitrogen $[S(t)]$ within the coupling time step is available for immobilization (step 1). If the total demand from all immobilizing processes $\left(F_{\text {immob }} \Delta t\right)$ is larger than the existing soil mineral nitrogen pool, all immobilizing fluxes are reduced to just deplete the existing soil mineral nitrogen pool (step 2), and new mineral nitrogen released from mobilizing processes $\left(F_{\mathrm{mob}} \Delta t\right)$ is saved for the next coupling time step (step 3; in the graphic example, the two blue boxes of newly mobilized nitrogen become two green boxes for use in the next coupling time step). In summary, under nitrogen limitation, MNL computes the actual uptake as

$$
\bar{F}_{\text {immob }}=F_{\text {immob }} \min \left\{1, \frac{S(t)}{F_{\text {immob }} \Delta t}\right\} .
$$

In the second scheme [Net Nitrogen Uptake-Based Limitation (NUL); third row of Figure 2], both the newly mobilized nitrogen and the existing soil mineral nitrogen within the coupling time step are available for uptake (step 1). During step 2, newly released mineral nitrogen from all mobilizing processes is first used to meet demands 
Earth Interactions - Volume 22 (2018) • Paper No. 11 • Page 5

\begin{tabular}{|l|c|}
\hline \multicolumn{1}{|c|}{ Step-1 } & Step-2 \\
\hline $\begin{array}{l}\text { MNL: } \\
\text { Mineral } \\
\text { Nitrogen } \\
\text { based } \\
\text { Limitation }\end{array}$ & \\
\hline NUL: \\
Net nitrogen \\
Uptake \\
based \\
Limitation
\end{tabular}

Figure 2. A graphic example of the three numerical nitrogen limitation schemes that are used to couple the nitrogen mobilizing processes ( $F_{\text {mob }} \Delta t$ : example magnitude of two boxes) and immobilizing processes ( $F_{\text {immob }} \Delta t$ : example magnitude of four boxes) with the soil mineral nitrogen pool $(S(t)$ : example magnitude of one box) at the beginning of a coupling time step. In applying the numerical schemes, step 1 identifies the total soil mineral nitrogen available for potential immobilization, step 2 computes the scaling ratio using the defined available nitrogen (upper stack of boxes) divided by effective immobilization flux (bottom stack of boxes), and step 3 gives the remaining soil mineral nitrogen (in green) for the next coupling time step $\Delta t$ and actual immobilization flux (in orange) within the current coupling time step. See text for further details. Note the red edges of the boxes are used to enhance the visual readability.

from all immobilizing processes, which leads to a net nitrogen demand (as designated by two remaining orange boxes in step 2 of our example in Figure 2) that is then compared to the existing soil mineral nitrogen pool over the coupling time step. If this net nitrogen demand is larger than the existing soil mineral nitrogen pool, then the total nitrogen demand is downscaled by the ratio of the existing soil mineral nitrogen pool to the net nitrogen demand. In our graphic example, only $50 \%$ of the net uptake is satisfied. However, because nitrogen mobilizing processes are independent from the soil mineral nitrogen pool $S(t)$, the scaling factor is then only applied to the original immobilization flux (designated by four orange boxes), resulting in the actual uptake being two orange boxes, and one green box of nitrogen is left over for use in the next coupling time step. In summary, NUL computes the actual uptake as

$$
\bar{F}_{\text {immob }}=F_{\text {immob }} \min \left\{1, \frac{S(t)}{\left(F_{\text {immob }}-F_{\text {mob }}\right) \Delta t}\right\} .
$$

Numerically, the NUL scheme is equivalent to the clipping method that truncates the derivative of a state variable to avoid negative physical state variables in some 
Earth Interactions - Volume 22 (2018) • Paper No. 11 • Page 6

solvers of MATLAB (Shampine et al. 2005) and also in numerical packages such as ARKODE (Reynolds et al. 2018), both of which are popular tools to develop biogeochemical models, either for research or operational use (e.g., Hong et al. 2005).

In the third scheme [Proportional Nitrogen Flux-Based Limitation (PNL); fourth row of Figure 2], the newly released and existing mineral nitrogen is first summed to obtain the total nitrogen available to support nitrogen immobilizing processes over the coupling time step (step 1; in the graphic example, this gives three boxes of soil mineral nitrogen to support immobilization). If the total demand from all nitrogen immobilizing processes is larger than the total available soil mineral nitrogen, the immobilizing fluxes are downscaled by the ratio between total available soil mineral nitrogen and total soil mineral nitrogen demand (step 2). In our example, the application of step 2 results in three orange boxes of soil mineral nitrogen being immobilized, and no soil mineral nitrogen is left for use in the next coupling time step (step 3). The Ecosys model (Grant 2013), which is a very comprehensive terrestrial ecosystem model that explicitly resolves microbial dynamics, aqueous chemistry, and plant-microbial coupling, is the only model that we are aware of that uses the PNL scheme (but, unfortunately, no published Ecosys paper has described the PNL scheme explicitly). The PNL scheme was also used (but without a technical description) in a simple model of nitrifiers we developed in Bouskill et al. (2012). Tang and Riley (2016) described the PNL scheme for dealing with multisubstrate colimitation in solving generic networks of biogeochemical reactions, but it has not been discussed in the context of ESM land biogeochemistry models. Mathematically, the PNL scheme computes the actual uptake as

$$
\bar{F}_{\text {immob }}=F_{\text {immob }}\left\{1, \frac{S(t)+F_{\mathrm{mob}} \Delta t}{F_{\text {immob }} \Delta t}\right\} .
$$

When the available soil mineral nitrogen over a coupling time step is larger than the sum of nitrogen immobilizing demands, all three schemes above will calculate equal soil mineral nitrogen immobilizing fluxes and, consequently, impose the same nitrogen effects on carbon fluxes. However, when the existing soil mineral nitrogen is insufficient to support the immobilizing demand, as is demonstrated with the orange boxes in step 3 in our graphic example in Figure 2, the MNL scheme will predict the strongest nitrogen limitation (because newly released soil mineral nitrogen is not available for uptake until the next coupling time step), and the PNL scheme will predict the weakest nitrogen limitation (because newly released nitrogen can be used within each coupling time step).

In soil, nitrogen mobilization and immobilization occur simultaneously (Schimel and Bennett 2004), and if diffusion does not limit the interactions between these processes (as is formulated in most current ESM land models), the existing and newly released mineral nitrogen is equally accessible for uptake. Therefore, PNL is the best among the three schemes to represent interactions between nitrogen mobilizing and immobilizing processes under nitrogen limiting conditions (and the PNL scheme can be proven to be consistent with the governing equation that describes the coupling between nitrogen mobilizing and immobilizing processes; see the appendix). However, because of its simplicity, MNL is used in CLM4, CLM4.5, and a few other models (e.g., Hidy and Barcza 2014; Parida 2011), and 
Earth Interactions - Volume 22 (2018) - Paper No. 11 • Page 7

NUL will be triggered if the popular clipping method is used (Tang and Riley 2016; Tang et al. 2016).

Moreover, even though the three methods are solving the same governing equation that represents plant-microbial competition for soil mineral nitrogen, the manner in which MNL and NUL ensure nonnegative soil mineral nitrogen pools during each model time step changes the assumed coupling between nitrogen mobilizing and immobilizing processes. Specifically, MNL makes nitrogen mobilization completely decoupled from immobilization, while NUL informs the influence of mobilization on immobilization inconsistently, such that the immobilization fluxes are adjusted based on the total derivative of $S(t)$ [which is $\left(F_{\text {mob }}-F_{\text {immob }}\right)$ ], while keeping $F_{\text {mob }}$ unchanged [because $F_{\text {mob }}$ is independent from $S(t)$ ]. Further, we note that in resolving such numerical difficulties, all highorder schemes will usually become first order (Bolley and Crouzeix 1978), even when the scheme is implicit (Hundsdorfer and Verwer 2003), unless the governing equations are reformulated to be less consistent with the conceptualization of the biogeochemical processes (e.g., Burchard et al. 2003).

Therefore, considering that the specifics of a numerical method may change how processes (mobilization vs immobilization here) are coupled, it is important to analyze whether the subtle differences among these three schemes will result in significant differences in predicted land-atmosphere carbon exchanges in longterm global simulations.

\subsection{Simulation protocols}

Our analyses consist of two groups of simulations for two time periods. For the historical period (1850-2000), one global simulation for each of the three nitrogencoupling schemes was performed at $1.9^{\circ} \times 2.5^{\circ}$ (longitude $\times$ latitude) spatial resolution by cycling the 1948-72 QIAN climate forcing data, which was constructed based on observation-constrained reanalysis products from the National Centers for Environmental Prediction-National Center for Atmospheric Research (Qian et al. 2006). Another global simulation using the default BGC implementation (i.e., ELM-v0, which is identical to CLM4.5) was performed for checking the consistency of the ELM-BeTR implementation [which demonstrated that ELM-BeTR-MNL differs from ELM-v0 with an expected increase in land carbon uptake due to ELM-BeTR's removal of nitrogen down-regulation of gross primary production (GPP); see detailed discussion in supplemental material]. Each global simulation used its own initial condition from the equilibrated spinup. Then the three ELM-BeTR simulations were extended to 2300, driven by RCP4.5 atmospheric $\mathrm{CO}_{2}$ and the cycling QIAN climate forcing. Unlike the RCP4.5 simulations reported in other studies (Hoffman et al. 2014; Shao et al. 2013), climate anomalies were not considered in our RCP4.5 simulations because taking them into account will only further increase the differences among the simulations (e.g., Tang and Zhuang 2008).

Four gridpoint simulations representing different ecosystem types at geographically and climatically distinct locations were conducted to facilitate more indepth analysis of the differences predicted by the three nitrogen-coupling schemes. This gridpoint-based analysis addresses two goals: 1) revealing the process-level sensitivity to the use of different coupling strategies and 2) analyzing time step size dependence of the PNL scheme (which is motivated by our previous study on 
Earth Interactions • Volume 22 (2018) - Paper No. 11 • Page 8

plant-soil hydrological coupling, where we found that a poor numerical implementation may result in model simulations being strongly dependent on model time step size; Tang et al. 2015). For each point, the 1850 initial condition was obtained from the spinup of PNL-adapt, that is, running PNL with the adaptive time stepping scheme from Tang and Riley (2016) for the soil biogeochemistry, which dynamically adjusts the time step size in a prediction-correction manner (Atkinson 1989). Processes other than soil biogeochemistry were run at the default 30-min time step. Using identical initial conditions from PNL-adapt removes the initial condition dependence of these grid-based comparisons. Further, since the adaptive time stepping was much more expensive than using the fixed 30-min time step, all reported global simulations were run with the default 30-min time step for all processes, and we do not expect that including global simulations with adaptive time step will affect the conclusions of this study.

\section{Results}

\subsection{Global simulations for $1850-2000$}

Of the three ELM-BeTR simulations, two contrasting types of differences were observed. For fast-response variables (i.e., those that demonstrate strong diurnal or seasonal cycles) such as GPP, net primary productivity (NPP), leaf area index (LAI), and ecosystem respiration (Figures $3 \mathrm{~b}-\mathrm{e}$ ), there are very small latitudinal differences. Differences between simulations are larger for slow-response variables (Figures $3 \mathrm{f}-\mathrm{i}$ ), particularly in soil (Figures 3f,g); these accumulate differences from the fast variables (note the units of those slow variables are petagrams, of which a small change in number could result in large changes in land-atmosphere carbon exchange). However, the differences are well within the range reported in multimodel comparisons (e.g., Beer et al. 2010; Ghimire et al. 2016; Song et al. 2017). The most notable differences between simulations are for cumulative net ecosystem exchange (NEE; which, like other slow-response variables, accumulates the effect from fast processes; Figure 3a;), where the MNL and NUL simulations are quite close to each other, with a difference of $28 \mathrm{PgC}$ by year 2000. In contrast, the PNL simulation predicted a significant land carbon loss between 1850 and $2000(-241 \mathrm{PgC})$. However, these values for the 1850 2000 total land carbon sink are comparable to the range reported for CMIP5 models, which vary from a $-150 \mathrm{PgC}$ source to $75 \mathrm{PgC}$ sink with respect to the atmosphere (Hoffman et al. 2014). For global SOM carbon to $1 \mathrm{~m}$ (Figure 3f), MNL predicts 2810 $\mathrm{PgC}$, NUL predicts $2798 \mathrm{PgC}$, and PNL predicts $2775 \mathrm{PgC}$, all of which are within the range of CMIP5 models (510 $3040 \mathrm{PgC}$; Todd-Brown et al. 2013) and are higher than current empirical estimates (1408 $\pm 154 \mathrm{PgC}$; Batjes 2016). Therefore, the three ELM-BeTR models are producing comparable uncertainty (with respect to CMIP5 models), with only subtle differences in the numerical coupling of nitrogen mobilizing and immobilizing processes.

\subsection{Global simulations driven by RCP4.5 atmospheric $\mathrm{CO}_{2}$}

Compared to the latitudinal distribution differences in global carbon and nitrogen stocks by year 2000 (Figures $3 \mathrm{f}-\mathrm{i}$ ), the differences in total carbon between 

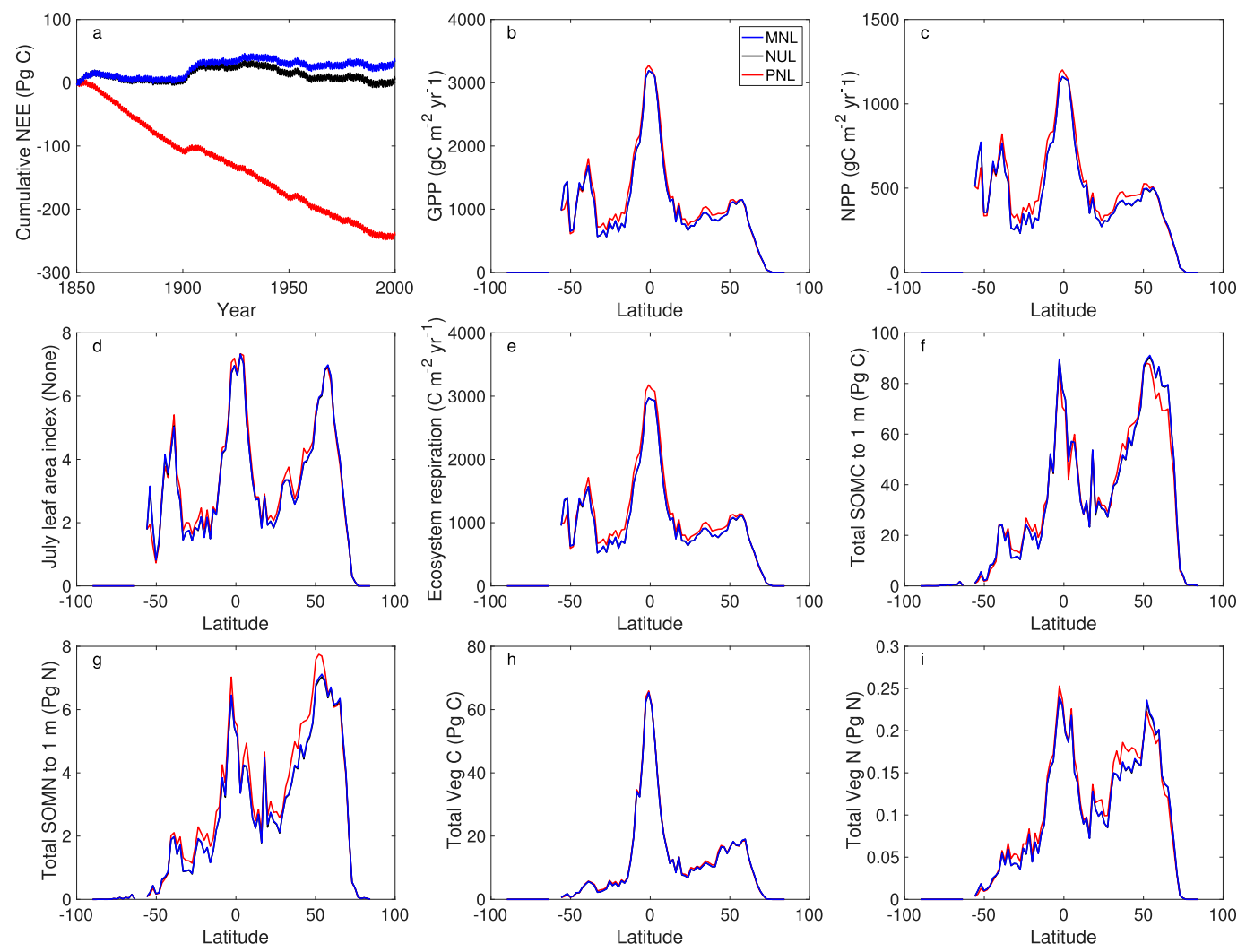

Figure 3. Comparison of global simulations for the historical period of 1850-2000. (a) Cumulative NEE (for better visualization, negative NEE implies carbon emission to the atmosphere, which is contrary to the standard use). (b) GPP. (c) NPP. (d) July LAI. (e) Ecosystem respiration. (f) Total organic soil carbon (including the three litter pools and three SOM pools) integrated to 1-m depth. (g) Total organic soil nitrogen (including the three litter pools and three SOM pools) integrated to $1-m$ depth. (h) Total vegetation carbon. (i) Total vegetation nitrogen. Results for (b)-(i) were averaged over 1991-2000 to indicate the accumulated influences of different coupling schemes on the analyzed variables. We note that (b)-(e) are considered fast-response variables, while (a) and (f)-(i) are considered slow-response variables. Except in (a), differences between MNL (blue line) and NUL (black line) are barely discernible.

PNL and the other two ELM-BeTR simulations increase dramatically after year 2001 (Figure 4). By year 2300, differences between simulations in the tropics $\left(23.2^{\circ} \mathrm{S}-23.2^{\circ} \mathrm{N}\right)$ are substantially larger than either northern temperate or Arctic regions (Figure 4), with a carbon gain of $\sim 1180 \mathrm{PgC}\left(19000 \mathrm{gC} \mathrm{m}^{-2}\right)$ predicted by $\mathrm{MNL}, \sim 1150 \mathrm{PgC}\left(18700 \mathrm{gC} \mathrm{m}^{-2}\right)$ by NUL, and $\sim 60 \mathrm{PgC}\left(5800 \mathrm{gC} \mathrm{m}^{-2}\right)$ by PNL. During the same time period, differences in predicted cumulative carbon uptake in the Arctic (latitudes $>66.3^{\circ} \mathrm{N}$ ) are the smallest among the three regions, with a carbon gain of $\sim 16 \mathrm{PgC}\left(1400 \mathrm{gC} \mathrm{m}^{-2}\right)$ predicted by MNL and NUL and $\sim 4 \mathrm{PgC}\left(340 \mathrm{gC} \mathrm{m}^{-2}\right)$ by PNL. 

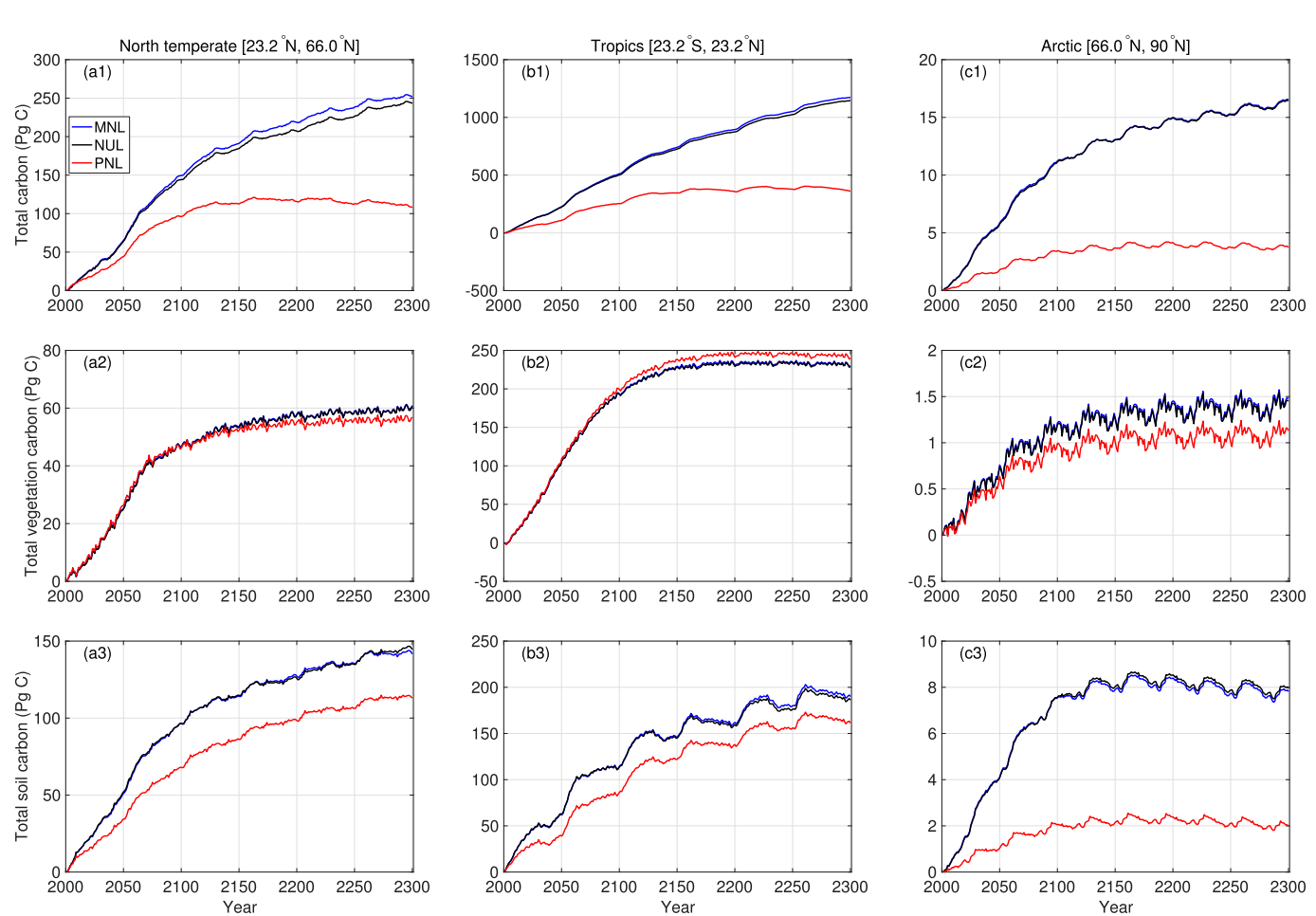

Figure 4. Comparison of model simulations forced by the RCP4.5 atmospheric $\mathrm{CO}_{2}$ for the period 2001-2300. Here, the total soil carbon includes carbon from the three litter pools and three soil organic matter pools as defined in CLM4.5 (Koven et al. 2013); coarse woody debris is excluded and presented as Figure $\mathrm{S} 3$ in the supplemental material, and numeric values from the first row are larger than the sum of the second and third rows. All changes are calculated relative to their initial carbon stocks at the beginning of the simulation (i.e., year 2000). The multidecadal oscillations are due to the cycling of the QIAN climate forcing.

Regions south of $23.2^{\circ} \mathrm{S}$ contributed a small fraction $(\sim 3 \%)$ of the difference in total terrestrial carbon stock changes by year 2300 (Figure 5). For 2006-2100, predicted changes in global terrestrial carbon stocks (Figure 5) range from $364 \mathrm{PgC}$ (sink) by PNL, to $667 \mathrm{PgC}$ (sink) by NUL, to $680 \mathrm{PgC}$ (sink) by MNL, giving a difference of $316 \mathrm{PgC}$. For comparison, Shao et al. (2013) reported that the eight RCP4.5 CMIP5 model simulations predicted a carbon sink ranging from 22 to 456 $\mathrm{PgC}$ for the same time period. Therefore, the predictive uncertainty resulting from subtle differences in the numerical coupling of nitrogen mobilizing and immobilizing processes is about $73 \%$ of the range of CMIP5 RCP4.5 simulations. Further, we note that the spread of our $\mathrm{CO}_{2}$-only simulations is much larger than that reported in Huntzinger et al. (2017), which, besides increasing atmospheric $\mathrm{CO}_{2}$, also considered land-use change, varying climate, and enhanced nitrogen deposition. This contrast suggests that the numerical uncertainty is comparably significant to combined uncertainty from model structural difference and forcing data, as reported in multimodel comparisons. 

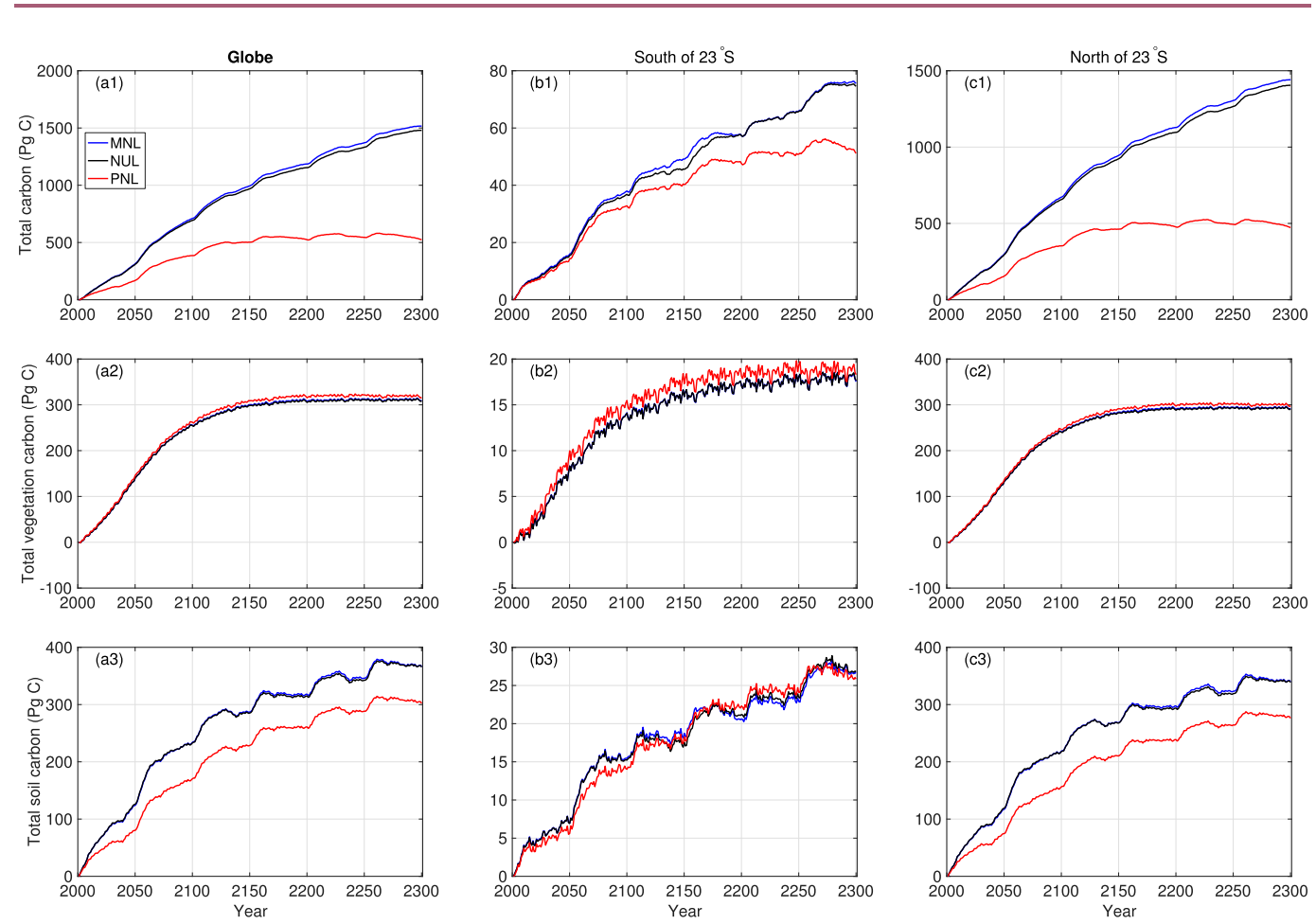

Figure 5. As in Figure 4, but this compares the changes in global and regional carbon stocks over $2000-2300$, as simulated by the three numerical coupling schemes for nitrogen immobilization and mobilization. The multidecadal oscillations as shown in the figure are due to the cycling of the QIAN climate forcing.

The differences in the terrestrial carbon stocks simulated by the three different model implementations are mostly in the soil (third row in Figures 4, 5) and coarse woody debris (Figure S3). Differences in vegetation carbon are relatively smaller (second row in Figures 4, 5), partly because the turnover time of vegetation carbon is generally much shorter than that of soil carbon and coarse woody debris (Koven et al. 2015). These intermodel differences suggest that with time, small differences in fast-response variables can accumulate and result in large differences in longterm soil carbon dynamics.

\section{Discussion}

The above analyses show that numerical methods used for coupling nitrogen immobilizing and mobilizing processes have large influences on simulated landatmosphere carbon exchanges. There are several reasons why this coupling is responsible for the simulated differences.

First, the modeled soil biogeochemistry is more sensitive to nitrogen dynamics than is vegetation biogeochemistry (Figure S4). In ELM-BeTR, the overall soil organic matter decomposition (of the three litter pools and three SOM pools) is limited by soil mineral nitrogen, suggesting that more effective soil mineral 
Earth Interactions - Volume 22 (2018) - Paper No. 11 • Page 12
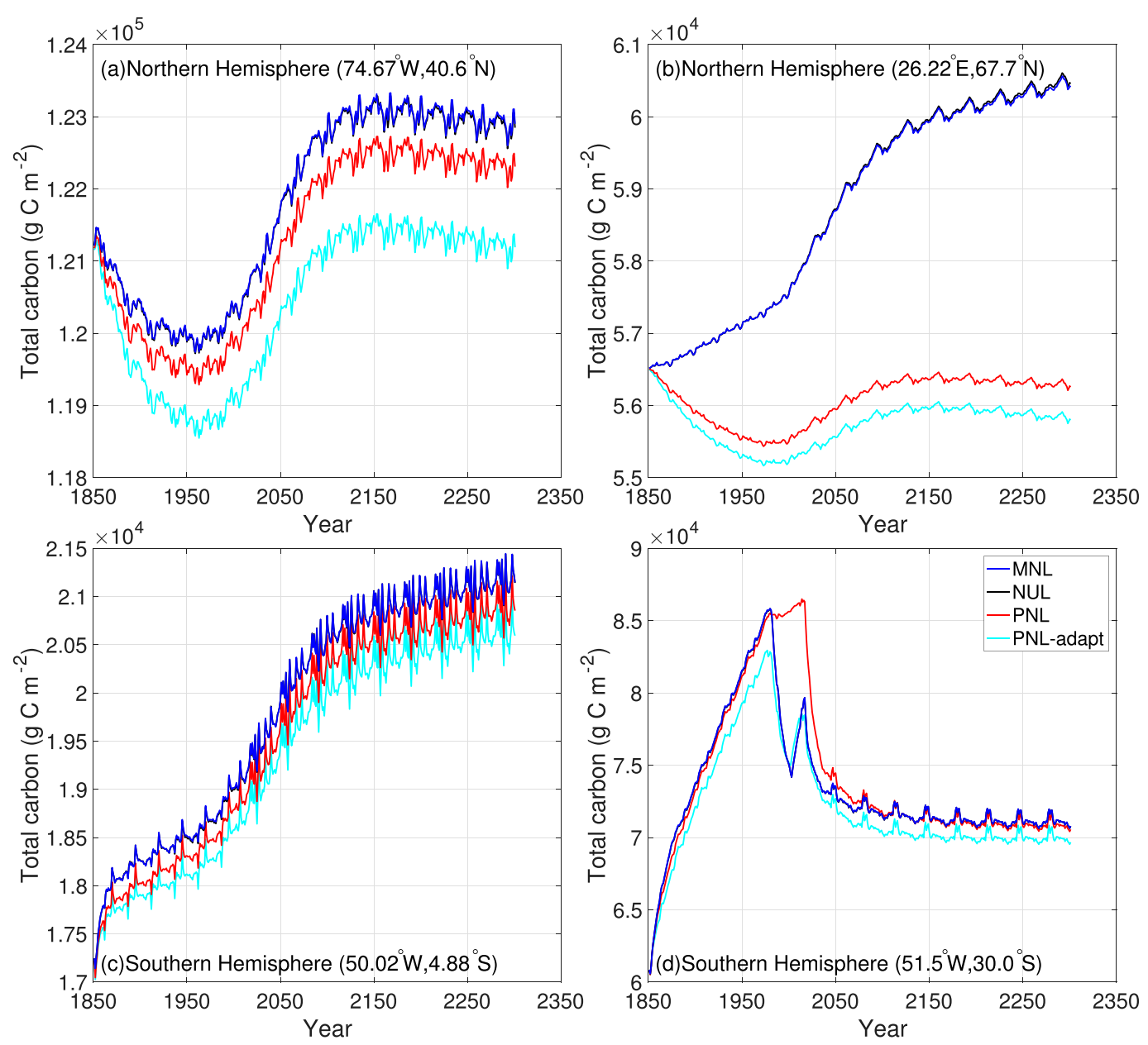

Figure 6. Comparison of point simulations for the four specific grid cells using different model configurations. For each site, all simulations used identical initial conditions obtained from spinup with the PNL-adapt code (which uses the adaptive time step coupling scheme from Tang and Riley (2016)). The multidecadal oscillations shown in the figure are due to the cycling of the QIAN climate forcing. The MNL and NUL simulations almost overlap each other, making their differences indiscernible.

nitrogen uptake by microbial processes will result in higher soil carbon losses. In our analysis, all model simulations used the same atmospheric nitrogen deposition data and predicted very similar nitrogen fixation rates and NPP, suggesting the uncertainty resulted mostly from nitrogen use (i.e., nitrogen immobilization). Among the three numerical coupling schemes, PNL exerted the weakest nitrogen limitation, and at ecosystem scale, PNL predicted the least land carbon sequestration in response to atmospheric $\mathrm{CO}_{2}$ enrichment (Figures 4-6), followed by NUL and MNL (which also explains the same decreasing order of total soil carbon stocks by year 2000, as discussed in section 3.1). In addition, predicted nitrogen losses (through denitrification, aqueous transport, fire, and nitrification $\mathrm{N}_{2} \mathrm{O}$ 
Earth Interactions - Volume 22 (2018) • Paper No. 11 • Page 13

emissions; Figure S5) are higher in the PNL simulation than both MNL and NUL, all of which drive the large differences in soil carbon stocks. Interestingly, although adaptive time step coupling tends to alleviate nitrogen limitation (by increasing nitrogen uptake frequency), nitrogen loss predicted by PNL-adapt was either higher or lower than that by PNL at the four sites we compared (Figures S5, S6), suggesting that coupling time step size is another subtle difference that might cause significant modeling uncertainty. However, unlike the time step size testing results in Tang et al. (2015), where the use of different time step sizes degraded model simulations, in our grid-based analysis (Figure 6) the influence of coupling time step size did not qualitatively change the overall trend of model responses to increasing atmospheric $\mathrm{CO}_{2}$, confirming that the PNL scheme is generally robust (Tang and Riley 2016).

Second, coarse woody debris dynamics are very sensitive to nitrogen dynamics and have a large effect on simulation differences (Du et al. 2017; Shi et al. 2016). In ELM-BeTR, coarse woody debris is a slow-response variable (and so is expected to be more sensitive to the choice of numerical coupling strategy) whose decomposition immobilizes nitrogen and increases soil carbon formation (as does litter organic matter decomposition). When nitrogen limitation is stronger, less coarse woody debris carbon is decomposed, and less soil carbon is formed. Therefore, PNL predicted the highest losses of coarse woody debris, followed by NUL and MNL (Figure S3). When soil carbon formation is combined with its decomposition, PNL predicted much lower soil carbon accumulation than did NUL and MNL (which are quite close; Figures 4, 5). Also, similar to CLM4, ELM-BeTR tends to overallocate carbon to woody biomass (Negrón-Juárez et al. 2015), particularly in the tropics, which, when combined with the different nitrogen limitation strengths predicted by the three coupling schemes, further contributed to intermodel differences.

\section{Conclusions}

By using ELM-BeTR, a reactive-transport-based land biogeochemical model, we showed that subtle numerical differences in how nitrogen immobilizing and mobilizing processes are coupled significantly influenced predictions of land-atmosphere carbon exchanges. Quantitatively, using RCP4.5 atmospheric $\mathrm{CO}_{2}$ forcing, the simulated differences resulting from three nitrogen-coupling schemes are about $73 \%$ of the uncertainty found in CMIP5 RCP4.5 model simulations. When combined with uncertainties from parameterizations, forcing data, and model formulations, we expect these models would have resulted in even larger differences in predicted land-atmosphere carbon exchanges. Our results, therefore, may help explain the reported inconsistent land carbon cycle responses to various environmental forcings across ESM-scale models (e.g., Hoffman et al. 2014; Huntzinger et al. 2017). Our results also suggest that resolving inconsistencies in numerical coupling of nitrogen immobilizing and mobilizing processes (and similarly for other newly added nutrients, e.g., phosphorus) may significantly improve model robustness and strengthen the foundation of using models to predict ecosystem responses to environmental changes.

Acknowledgments. This research was supported by the Director, Office of Science, Office of Biological and Environmental Research of the U.S. Department of Energy under 
Earth Interactions • Volume 22 (2018) • Paper No. 11 • Page 14

Contract DE-AC02-05CH11231 as part of the Energy Exascale Earth System Model project in the Earth System Modeling program, and the Regional and Global Climate Modeling (RGCM) Program. The study used the Lawrencium computational cluster resource provided by the IT division at the Lawrence Berkeley National Laboratory. The data used in this paper can be obtained by contacting the first author at jinyuntang@lbl.gov. We also sincerely thank three anonymous reviewers for their constructive comments, which significantly improved the presentation of this work.

\section{Appendix: Proof of the Consistency of the PNL Scheme}

After applying the process split method (so that other biogeochemical processes are treated separately from the coupling of nitrogen mobilization and immobilization; Strang 1968), the governing equation that describes the coupling between nitrogen mobilizing and immobilizing processes is

$$
\frac{d S}{d t}=F_{\mathrm{mob}}-F_{\mathrm{immob}}
$$

By discretizing Equation (A1) using the finite difference method (Atkinson 1989), we have

$$
S(t+\Delta t)=S(t)+\Delta t\left(F_{\mathrm{mob}}-\bar{F}_{\mathrm{immob}}\right)+o(\Delta t),
$$

where the actual immobilization flux in Equation (A2) has been included, and $o(\Delta t)$ represents higher-order terms.

When nutrient $S(t)$ is limited, all mineral nitrogen should disappear after immobilization, which suggests $S(t+\Delta t)=0$ as $\Delta t$ approaches zero.

This thus requires

$$
S(t)+\Delta t\left(F_{\mathrm{mob}}-\bar{F}_{\mathrm{immob}}\right)=0 .
$$

By invoking the PNL scheme [i.e., Equation (3)] for the nitrogen limiting condition, we have

$$
S(t)+F_{\mathrm{mob}} \Delta t-F_{\mathrm{immob}} \Delta t \frac{S(t)+F_{\mathrm{mob}} \Delta t}{F_{\mathrm{immob}} \Delta t}=0,
$$

which proves the consistency of the PNL scheme with respect to Equation (A1). Further, it can be verified that neither the MNL nor NUL scheme satisfies Equation (A3). Therefore, MNL and NUL are not consistent with the governing Equation (A1).

\section{References}

Arakawa, A., 1966: Computational design for long-term numerical integration of the equations of fluid motion: Two-dimensional incompressible flow. Part I. J. Comput. Phys., 1, 119-143, https://doi.org/10.1016/0021-9991(66)90015-5.

Atkinson, K., 1989: An Introduction to Numerical Analysis. Wiley, 712 pp.

Batjes, N. H., 2016: Harmonized soil property values for broad-scale modelling (WISE30sec) with estimates of global soil carbon stocks. Geoderma, 269, 61-68, https://doi.org/10.1016/j. geoderma.2016.01.034. 
Earth Interactions - Volume 22 (2018) • Paper No. 11 • Page 15

Beer, C., and Coauthors, 2010: Terrestrial gross carbon dioxide uptake: Global distribution and covariation with climate. Science, 329, 834-838, https://doi.org/10.1126/science.1184984.

Blanke, J. H., M. Lindeskog, J. Lindström, and V. Lehsten, 2016: Effect of climate data on simulated carbon and nitrogen balances for Europe. J. Geophys. Res. Biogeosci., 121, 13521371, https://doi.org/10.1002/2015JG003216.

Bolley, C., and M. Crouzeix, 1978: Conservation de la positivité lors de la discrétrisation des problèmes d'évolution parabolique. R. A. I. R. O. Numer. Anal., 12, 237-245, https://doi.org/ 10.1051/m2an/1978120302371.

Bouskill, N. J., J. Y. Tang, W. J. Riley, and E. L. Brodie, 2012: Trait-based representation of biological nitrification: Model development, testing, and predicted community composition. Front. Microbiol., 3, 364, https://doi.org/10.3389/fmicb.2012.00364.

— W W. J. Riley, and J. Y. Tang, 2014: Meta-analysis of high-latitude nitrogen-addition and warming studies implies ecological mechanisms overlooked by land models. Biogeosciences, 11, 6969-6983, https://doi.org/10.5194/bg-11-6969-2014.

Broekhuizen, N., G. J. Rickard, J. Bruggeman, and A. Meister, 2008: An improved and generalized second order, unconditionally positive, mass conserving integration scheme for biochemical systems. Appl. Numer. Math., 58, 319-340, https://doi.org/10.1016/j. apnum.2006.12.002.

Burchard, H., E. Deleersnijder, and A. Meister, 2003: A high-order conservative Patankar-type discretisation for stiff systems of production-destruction equations. Appl. Numer. Math., 47, 1-30, https://doi.org/10.1016/S0168-9274(03)00101-6.

Clein, J., A. D. McGuire, E. S. Euskirchen, and M. Calef, 2007: The effects of different climate input datasets on simulated carbon dynamics in the western Arctic. Earth Interact., 11, 1-24, https://doi.org/10.1175/EI229.1.

De Kauwe, M. G., and Coauthors, 2017: Challenging terrestrial biosphere models with data from the long-term multifactor Prairie Heating and $\mathrm{CO}_{2}$ Enrichment experiment. Global Change Biol., 23, 3623-3645, https://doi.org/10.1111/gcb.13643.

Du, Z. G., and Coauthors, 2017: Quantifying uncertainties from additional nitrogen data and processes in a terrestrial ecosystem model with Bayesian probabilistic inversion. $J$. Adv. Model. Earth Syst., 9, 548-565, https://doi.org/10.1002/2016MS000687.

Friedlingstein, P., M. Meinshausen, V. K. Arora, C. D. Jones, A. Anav, S. K. Liddicoat, and R. Knutti, 2014: Uncertainties in CMIP5 climate projections due to carbon cycle feedbacks. J. Climate, 27, 511-526, https://doi.org/10.1175/JCLI-D-12-00579.1.

Ghimire, B., W. J. Riley, C. D. Koven, M. Q. Mu, and J. T. Randerson, 2016: Representing leaf and root physiological traits in CLM improves global carbon and nitrogen cycling predictions. J. Adv. Model. Earth Syst., 8, 598-613, https://doi.org/10.1002/2015MS000538.

Goll, D. S., and Coauthors, 2012: Nutrient limitation reduces land carbon uptake in simulations with a model of combined carbon, nitrogen and phosphorus cycling. Biogeosciences, $\mathbf{9}$, 3547-3569, https://doi.org/10.5194/bg-9-3547-2012.

— A. J. Winkler, T. Raddatz, N. Dong, I. C. Prentice, P. Ciais, and V. Brovkin, 2017a: Carbonnitrogen interactions in idealized simulations with JSBACH (version 3.10). Geosci. Model Dev., 10, 2009-2030, https://doi.org/10.5194/gmd-10-2009-2017.

— 4520). Geosci. Model Dev., 10, 3745-3770, https://doi.org/10.5194/gmd-10-3745-2017.

Grant, R. F., 2013: Modelling changes in nitrogen cycling to sustain increases in forest productivity under elevated atmospheric $\mathrm{CO}_{2}$ and contrasting site conditions. Biogeosciences, 10, 77037721, https://doi.org/10.5194/bg-10-7703-2013.

Hidy, D., and Z. Barcza, 2014: User's guide for Biome-BGC MuSo v3.0. Biome-BGC MuSo Tech. Rep., 43 pp.

Hoffman, F. M., and Coauthors, 2014: Causes and implications of persistent atmospheric carbon dioxide biases in Earth system models. J. Geophys. Res. Biogeosci., 119, 141-162, https:// doi.org/10.1002/2013JG002381. 


\section{Earth Interactions • Volume 22 (2018) • Paper No. 11 • Page 16}

Hong, B. G., R. L. Strawderman, D. P. Swaney, and D. A. Weinstein, 2005: Bayesian estimation of input parameters of a nitrogen cycle model applied to a forested reference watershed, Hubbard Brook Watershed Six. Water Resour. Res., 41, W03007, https://doi.org/10.1029/ 2004WR003551.

Houlton, B. Z., A. R. Marklein, and E. Bai, 2015: Representation of nitrogen in climate change forecasts. Nat. Climate Change, 5, 398-401, https://doi.org/10.1038/nclimate2538.

Hundsdorfer, W., and J. G. Verwer, 2003: Numerical Solution of Time-Dependent Advection-Diffusion-Reaction Equations. Springer Series in Computational Mathematics, Vol. 33., Springer, $472 \mathrm{pp}$.

Huntzinger, D. N., and Coauthors, 2012: North American Carbon Program (NACP) regional interim synthesis: Terrestrial biospheric model intercomparison. Ecol. Modell., 232, 144-157, https://doi.org/10.1016/j.ecolmodel.2012.02.004.

— drivers undermines carbon-climate feedback predictions. Sci. Rep., 7, 4765, https://doi.org/ 10.1038/s41598-017-03818-2.

Koven, C. D., and Coauthors, 2013: The effect of vertically resolved soil biogeochemistry and alternate soil C and N models on C dynamics of CLM4. Biogeosciences, 10, 7109-7131, https://doi.org/10.5194/bg-10-7109-2013.

— over in the CMIP5 Earth system models. Biogeosciences, 12, 5211-5228, https://doi.org/ 10.5194/bg-12-5211-2015.

LeBauer, D. S., and K. K. Treseder, 2008: Nitrogen limitation of net primary productivity in terrestrial ecosystems is globally distributed. Ecology, 89, 371-379, https://doi.org/10.1890/ 06-2057.1.

Luo, Z. K., E. L. Wang, H. Zheng, J. A. Baldock, O. J. Sun, and Q. Shao, 2015: Convergent modelling of past soil organic carbon stocks but divergent projections. Biogeosciences, 12, 4373-4383, https://doi.org/10.5194/bg-12-4373-2015.

_ _ - and O. J. Sun, 2017: Uncertain future soil carbon dynamics under global change predicted by models constrained by total carbon measurements. Ecol. Appl., 27, 1001-1009, https://doi.org/10.1002/eap.1504.

Negrón-Juárez, R. I., C. D. Koven, W. J. Riley, R. G. Knox, and J. Q. Chambers, 2015: Observed allocations of productivity and biomass, and turnover times in tropical forests are not accurately represented in CMIP5 Earth system models. Environ. Res. Lett., 10, 064017, https:// doi.org/10.1088/1748-9326/10/6/064017.

Nguyen, K., A. Caboussat, and D. Dabdub, 2009: Mass conservative, positive definite integrator for atmospheric chemical dynamics. Atmos. Environ., 43, 6287-6295, https://doi.org/ 10.1016/j.atmosenv.2009.09.032.

Oleson, K. W., and Coauthors, 2010: Technical description of version 4.0 of the Community Land Model (CLM). NCAR Tech. Note NCAR/TN-478+STR, 266 pp., https://doi.org/10.5065/ D6FB50WZ.

— (CLM). NCAR Tech. Note NCAR/TN-503+STR, 422 pp., https://doi.org/10.5065/D6RR1W7M.

Parida, B., 2011: The influence of plant nitrogen availability on the global carbon cycle and $\mathrm{N}_{2} \mathrm{O}$ emissions. MPI Rep. on Earth System Science, 158 pp., http://www.mpimet.mpg.de/ fileadmin/publikationen/Reports/WEB_BzE_92.pdf.

Petrovskii, S., and N. Petrovskaya, 2012: Computational ecology as an emerging science. Interface Focus, 2, 241-254, https://doi.org/10.1098/rsfs.2011.0083.

Phillips, N. A., 1956: The general circulation of the atmosphere: A numerical experiment. Quart. J. Roy. Meteor. Soc., 82, 123-164, https://doi.org/10.1002/qj.49708235202.

Qian, T. T., A. Dai, K. E. Trenberth, and K. W. Oleson, 2006: Simulation of global land surface conditions from 1948 to 2004. Part I: Forcing data and evaluations. J. Hydrometeor., 7, 953975, https://doi.org/10.1175/JHM540.1. 


\section{Earth Interactions - Volume 22 (2018) • Paper No. 11 • Page 17}

Reynolds, D. R., D. J. Gardner, A. C. Hindmarsh, C. S. Woodward, and J. M. Sexton, 2018: User documentation for ARKode v2.1.1 (SUNDIALS v3.1.1). LLNL Tech. Rep. LLNL-SM668082, 299 pp., https://computation.llnl.gov/sites/default/files/public/ark_guide.pdf.

Sandu, A., 2001: Positive numerical integration methods for chemical kinetic systems. J. Comput. Phys., 170, 589-602, https://doi.org/10.1006/jcph.2001.6750.

Schimel, J. P., and J. Bennett, 2004: Nitrogen mineralization: Challenges of a changing paradigm. Ecology, 85, 591-602, https://doi.org/10.1890/03-8002.

Shampine, L. F., S. Thompson, J. A. Kierzenka, and G. D. Byrne, 2005: Non-negative solutions of ODEs. Appl. Math. Comput., 170, 556-569.

Shao, P., X. B. Zeng, K. Sakaguchi, R. K. Monson, and X. D. Zeng, 2013: Terrestrial carbon cycle: Climate relations in eight CMIP5 Earth system models. J. Climate, 26, 8744-8764, https:// doi.org/10.1175/JCLI-D-12-00831.1.

Shi, Z., Y. H. Yang, X. H. Zhou, E. S. Weng, A. C. Finzi, and Y. Q. Luo, 2016: Inverse analysis of coupled carbon-nitrogen cycles against multiple datasets at ambient and elevated $\mathrm{CO}_{2}$. J. Plant Ecol., 9, 285-295, https://doi.org/10.1093/jpe/rtv059.

Song, X., F. M. Hoffman, C. M. Iversen, Y. H. Yin, J. Kumar, C. Ma, and X. F. Xu, 2017: Significant inconsistency of vegetation carbon density in CMIP5 Earth system models against observational data. J. Geophys. Res. Biogeosci., 122, 2282-2297, https://doi.org/10.1002/ 2017JG003914.

Strang, G., 1968: On the construction and comparison of difference schemes. SIAM J. Numer. Anal., 5, 506-517, https://doi.org/10.1137/0705041.

Tang, G., and Coauthors, 2016: Addressing numerical challenges in introducing a reactive transport code into a land surface model: A biogeochemical modeling proof-of-concept with CLM-PFLOTRAN 1.0. Geosci. Model Dev., 9, 927-946, https://doi.org/10.5194/ gmd-9-927-2016.

Tang, J. Y., and Q. L. Zhuang, 2008: Equifinality in parameterization of process-based biogeochemistry models: A significant uncertainty source to the estimation of regional carbon dynamics. J. Geophys. Res., 113, G04010, https://doi.org/10.1029/2008JG000757.

_ and W. J. Riley, 2016: Technical note: A generic law-of-the-minimum flux limiter for simulating substrate limitation in biogeochemical models. Biogeosciences, 13, 723-735, https:// doi.org/10.5194/bg-13-723-2016.

, - C. D. Koven, and Z. M. Subin, 2013: CLM4-BeTR, a generic biogeochemical transport and reaction module for CLM4: Model development, evaluation, and application. Geosci. Model Dev., 6, 127-140, https://doi.org/10.5194/gmd-6-127-2013.

,-- , and J. Niu, 2015: Incorporating root hydraulic redistribution in CLM4.5: Effects on predicted site and global evapotranspiration, soil moisture, and water storage. J. Adv. Model. Earth Syst., 7, 1828-1848, https://doi.org/10.1002/2015MS000484.

Taylor, K. E., R. J. Stouffer, and G. A. Meehl, 2012: An overview of CMIP5 and the experiment design. Bull. Amer. Meteor. Soc., 93, 485-498, https://doi.org/10.1175/BAMS-D-11-00094.1.

Thornton, P. E., J. F. Lamarque, N. A. Rosenbloom, and N. M. Mahowald, 2007: Influence of carbon-nitrogen cycle coupling on land model response to $\mathrm{CO} 2$ fertilization and climate variability. Global Biogeochem. Cycles, 21, GB4018, https://doi.org/10.1029/ 2006 GB002868.

Todd-Brown, K. E. O., J. T. Randerson, W. M. Post, F. M. Hoffman, C. Tarnocai, E. A. G. Schuur, and S. D. Allison, 2013: Causes of variation in soil carbon simulations from CMIP5 Earth system models and comparison with observations. Biogeosciences, 10, 1717-1736, https:// doi.org/10.5194/bg-10-1717-2013.

Vitousek, P. M., and R. W. Howarth, 1991: Nitrogen limitation on land and in the sea: How can it occur? Biogeochemistry, 13, 87-115, https://doi.org/10.1007/BF00002772.

Wan, H., P. J. Rasch, K. Zhang, J. Kazil, and L. R. Leung, 2013: Numerical issues associated with compensating and competing processes in climate models: An example from ECHAM-HAM. Geosci. Model Dev., 6, 861-874, https://doi.org/10.5194/gmd-6-861-2013. 
Earth Interactions - Volume 22 (2018) • Paper No. 11 • Page 18

— K. K. Zhang, P. J. Rasch, B. Singh, X. Y. Chen, and J. Edwards, 2017: A new and inexpensive non-bit-for-bit solution reproducibility test based on time step convergence (TSC1.0). Geosci. Model Dev., 10, 537-552, https://doi.org/10.5194/gmd-10-537-2017.

Wieder, W. R., C. C. Cleveland, W. K. Smith, and K. Todd-Brown, 2015a: Future productivity and carbon storage limited by terrestrial nutrient availability. Nat. Geosci., 8, 441-444, https:// doi.org/10.1038/ngeo2413.

, — D. M. Lawrence, and G. B. Bonan, 2015b: Effects of model structural uncertainty on carbon cycle projections: Biological nitrogen fixation as a case study. Environ. Res. Lett., 10, 044016, https://doi.org/10.1088/1748-9326/10/4/044016.

Zaehle, S., and Coauthors, 2014: Evaluation of 11 terrestrial carbon-nitrogen cycle models against observations from two temperate Free-Air $\mathrm{CO}_{2}$ Enrichment studies. New Phytol., 202, $803-$ 822, https://doi.org/10.1111/nph.12697.

Zhu, Q., W. J. Riley, J. Y. Tang, and C. D. Koven, 2016a: Multiple soil nutrient competition between plants, microbes, and mineral surfaces: Model development, parameterization, and example applications in several tropical forests. Biogeosciences, 13, 341-363, https://doi.org/10.5194/ bg-13-341-2016.

— C. M. Iversen, W. J. Riley, I. J. Slette, and H. M. Vander Stel, 2016b: Root traits explain observed tundra vegetation nitrogen uptake patterns: Implications for trait-based land models. J. Geophys. Res. Biogeosci., 121, 3101-3112, https://doi.org/10.1002/2016JG003554.

— W. W. Riley, and J. Y. Tang, 2017: A new theory of plant-microbe nutrient competition resolves inconsistencies between observations and model predictions. Ecol. Appl., 27, 875886, https://doi.org/10.1002/eap.1490.

Earth Interactions is published jointly by the American Meteorological Society, the American Geophysical Union, and the Association of American Geographers. For information regarding reuse of this content and general copyright information, consult the AMS Copyright Policy (www.ametsoc.org/PUBSReuseLicenses). 